\title{
A serotonina inibe reações de pânico? Um estudo de depleção de triptofano em pacientes portadores de transtorno de pânico em remissão após tratamento com paroxetina
}

\author{
Bell C., Forshall S., Adrover M. et al. Does 5-HT restrain panic? A tryptophan depletion study in panic \\ disorder patients recovered on paroxetine. J Psychopharmacol 16(1): 5-14, 2002 \\ Comentado por Márcio Antonini Bernik
}

\section{Recebido: 19/5/2003 Aceito: 5/6/2003}

O sistema serotonérgico parece ter efeitos contraditórios sobre a expressão de sintomas de ansiedade. De modo a melhor entender as evidências convergentes, Deakin e Graeff (1991) propuseram um modelo em que a resposta de ansiedade a riscos distantes induziram respostas de ansiedade antecipatória potencializadas por aferências excitatórias 5 -HT provenientes do núcleo medial da rafe para a amígdala e a porção CA3 do hipocampo em que ativariam receptores do tipo $2 \mathrm{C}$ pós-sinápticos. Por outro lado, as aferências provenientes do núcleo dorsal da rafe apresentariam efeito inibitório sobre a substância cinzenta periarquedutal que controlaria respostas de fuga ou luta espécie-específicas. Essas reações são postuladas pelos autores como envolvidas na fisiopatologia dos ataques de pânico em humanos.

Para testar essa hipótese, Bell et al., em trabalho realizado no Serviço do Prof. David Nutt na Universidade de Bristol, realizaram um estudo de depleção aguda de triptofano (metodologia descrita em Young et al., 1985) em 14 sujeitos com transtorno de pânico que haviam conseguido remissão total dos sintomas com a administração de um antidepressivo de ação preferencialmente serotonérgica, a paroxetina.

Os pacientes ingeriram, em duas situações distintas, uma solução destituída de triptofano ou uma solução controle, sendo a primeira solução capaz de reduzir em $87 \%$ as concentrações plasmáticas de triptofano.

Observaram-se crises de pânico induzidas pelo teste provocativo com flumazenil em 7 dos 14 pacientes que receberam a droga ativa flumazenil em um estado de depleção de serotonina e em apenas 1 deles na situação controle.

A importância deste estudo foi que pela primeira vez demonstrou-se que, em pacientes com transtorno de pânico tratados com antidepressivos serotonérgicos, a manutenção de uma biodisponibilidade elevada de serotonina está associada com seu efeito na terapia de manutenção.

\section{Referências bibliográficas}

Deakin, J.F.W.; GraefF, F.G. - 5-HT and Mechanisms of Defence. J Psychopharmacol 5: 305-15, 1991.

Young, S.N.; Smith, S.E.; Pinl, R.O.; Erwin, P.R. - Tryptophan depletion Causes a Rapid Lowering of Mood in Normal Males. Psychopharmacology 87: 173-7, 1985.
Coordenador do AMBAN - Instituto de Psiquiatria do HCFMUSP.

Endereço para correspondência:

Instituto e Departamento de Psiquiatria da FMUSP

Rua Dr. Ovídio Pires de Campos s/n, São Paulo, SP - CEP 05403-010

E mail: marcio.bernik.uol.com.br 